\title{
A EDUCAÇÃO PARA O RESPEITO À LIBERDADE DE CRENÇA COMO ESTRATÉGIA PREVENTIVA DE CONFLITOS RELIGIOSOS NO BRASIL
}

\author{
Eliana Cristina dos Santos Farcic ${ }^{1}$ \\ Mônica Pereira Pilon ${ }^{2}$ \\ Aline Ouriques Freire Fernandes ${ }^{3}$
}

\section{Resumo:}

Os conflitos de ordem religiosa afetam as sociedades ocidentais há séculos, diante disso, surgem necessidades reais de discutir a incidência de conflitos. O objetivo do artigo é analisar a relevância da educação para a liberdade de crença como meio de prevenir e gerir os conflitos religiosos no Brasil. A educação tem papel fundamental no trabalho da promoção da valorização da diversidade cultural religiosa brasileira e pode ser utilizada como estratégia da diminuição dos conflitos. No entanto, é necessário um trabalho na formação inicial dos professores, para que realmente sejam promotores de uma educação laica, pautada no respeito e na paz.

Palavras-chave: conflito; direitos fundamentais;ordem religiosa; educação; Brasil

\section{EDUCATION TO RESPECT FREEDOM OF BELIEF AS A PREVENTIVE STRATEGY FOR RELIGIOUS CONFLICTS IN BRAZIL}

\begin{abstract}
:
Conflicts of religious nature have affected western societies for centuries, presenting the dire necessity to discuss the incidence of these conflicts. The aim of this paper is to analyze the importance of education for freedom of belief we means of preventing and managing religious conflicts in Brazil. Education had a fundamental role in promoting the acknowledgement of brazilian religious and cultural diversity and may be used as a strategy to minimize conflicts. It is, however, necessary to work on the initial training of teachers so they can be advocates of a secular education based on respect and peace.
\end{abstract}

Keywords: conflict, fundamental rights, religious order;education;Brazil

\section{INTRODUÇÃO}

Nota-se que a história da humanidade é marcada por conflitos e desentendimentos nas mais diversas searas, o que motiva e inspira investigações acerca das origens, intensidades

\footnotetext{
${ }^{1}$ Mestranda em Gestão de Conflitos no Mestrado Profissional em Direito da Uniara, Advogada, conciliadora e mediadora. - e-mail: ecdsfarci@uniara.edu.br - . Carlos Gomes, 1217 - Centro, Araraquara - SP, 14801-340;

${ }^{2}$ Pedagoga, Mestre e Doutora pela UFSCAR, docente na Uniara - e-mail: monica.uniara@gmail.com - . Carlos Gomes, 1217 - Centro, Araraquara - SP, 14801-340;

3 Advogada, Doutora em Função Social do Direito e Acesso à Justiça pela FADISP, docente do Mestrado Profissional em Direito da Uniara - e-mail: aoffernandes@uniara.edu.br - . Carlos Gomes, 1217 - Centro, Araraquara - SP, 14801-340.
} 
e modalidades. De um modo geral, esses conflitos são em sua maioria por pensamentos distintos principalmente no que diz respeito às religiões, percebe-se que a busca por alternativas de resolução e/ou composição dos credos de forma pacífica estão entre os estudos mais antigos da história do homem. É uma forma de pensamento embrionado no campo da sociologia e da economia política antes mesmo do surgimento das escolas de pensamentos da Grécia (BARBANTI JR, 2002). Com o amadurecimento, este tema tornou-se multidisciplinar, dotado de diferentes abordagens e interpretações e aplicado em uma infinidade de áreas (BARBANTI JR, 2002; VARGAS, 2007). Atualmente, encontram-se pensamentos no campo da engenharia, da administração pública, da economia, da saúde, da educação, do direito, e da biologia (GRANJA; WARNER, 2006; WIENS, 2008). Dentre o leque de questões, os estudos abordam, entre outros assuntos, a temática dos conflitos religiosos (BOICU, 2019; MAYER, 2013; CARLS, 2019).

Salienta-se que a religião se apresenta como um conjunto de ideias, sentimentos e ações compartilhadas por um grupo; é uma forma de consciência social caracterizada pela fé em uma divindade, em um ser sobrenatural que fornece àqueles que o abraçam um objeto de adoração, um código comportamental, um quadro de referência para o relacionamento com seu próprio grupo sócio religioso (BOICU, 2019). Geralmente visa acalmar a violência e impedir sua explosão, mas, mesmo assim, é constantemente dominado por conflitos e contradições (BOICU, 2019), uma vez que alimenta emoções fortes e liga as definições cognitivas da realidade com as estruturas de sentimento e obrigação, ao fazê-lo, pode autorizar, legitimar, habilitar e até exigir ação violenta diante de ameaças urgentes, profanações de símbolos sagrados e extrema alteridade (MAYER, 2013).

Estudos do conflito religioso contemporâneo emergem para a maior parte das disciplinas de estudos religiosos e ciências sociais e concentram-se em vários aspectos, tais como as causas principais (que podem ser as linhas de pensamento e ideologia); condições de afloramento; e mais recentemente, os mecanismos de resolução / reconciliação (MAYER, 2013). É exatamente, nessa terceira linha, que este artigo se posiciona. Esses mecanismos de resolução/conciliação desenvolvem ações junto aos grupos que causam e os que são alvos da violência (MAYER, 2013).

É sabido que os conflitos de ordem religiosa afetam as sociedades ocidentais há séculos, geralmente de maneira dramática e enraizados nos debates sobre o aborto, ensino em escolas públicas, liberdade de expressão e blasfêmia, por exemplo (CARLS, 2019). Surgem 
necessidades reais de discutir a incidência de conflitos, particularmente, em sociedades marcadas pelo aumento da diversidade religiosa, tal qual o caso do Brasil. Em paralelo e em complemento, se justifica, pois, além de identificar a essência do conflito, é importante ainda, propor soluções para efetivar e otimizar a gestão desses conflitos, principalmente, no bojo das discussões dos novos direitos, sendo esta precisamente, a ideia central do artigo, que se propõe a analisar a relevância da educação para a liberdade de crença como meio de prevenir e gerir os conflitos religiosos no Brasil. Evidencia-se que a religião cria um regime de verdade e um código moral obrigatório, é necessário produzir pesquisas que forneçam uma estrutura de análise e uma identificação das formas como as sociedades modernas lidam com o pluralismo religioso. Sendo estas, umas das possíveis contribuições do artigo.

Justifica-se ainda, pois, a intolerância como sendo uma forma de expressão associada ao fanatismo ligado ao sagrado e pela não aceitação do "diferente". Atualmente, com a globalização, a intolerância tem crescido de forma desordenada e violenta por grupos extremistas. Diariamente, noticiários internacionais retratam a triste realidade de práticas de terrorismo motivadas por conflitos religiosos. Dentre muitos relatos, pode-se destacar: Ataques a Mesquitas, Templos Budistas, Igrejas dentre outros Templos de diferentes cultos. Em uma carta póstuma, "Fé, fanatismos, "Islamofobia" e humor", o cartunista Charb, morto em um ataque terrorista, conhecido como o massacre de Charlie Hebdo, faz uma crítica sofisticada à uma sociedade incapaz de integrar os imigrantes, ou seja, por conta do Terrorismo, vários países restringem e negam vistos de entrada para refugiados de guerra.

\section{A RELIGIÃO: DEFINIÇÃO, ESCOPO E A LIBERDADE DE CRER}

Oriunda da palavra em latim religio, entende-se por religião o sentimento nutrido por um indivíduo direcionado ao que considera sagrado. Neste sentido pode-se chamar de devoção, crença ou fé. É responsável por aproximar o de uma força espiritual elevada, na qual o ele busca através de práticas religiosas sanar problemas, superar dificuldades e alcançar a felicidade plena. Toda religião tem seus fundamentos, umas possuem seus alicerces construídos com base em análises filosóficas, outras simplesmente exploram o poder da fé ("o crer sem ver") e por fim temos aquelas que estão edificadas em um extenso conteúdo ético e moral. Por religião entende-se também ser um conjunto de práticas doutrinárias, crenças e princípios, reunindo em uma mesma comunidade moral, seus adeptos. Estes locais são 
denominados Igrejas, Mesquitas, Templos, dentre outras denominações ao qual cada grupo religioso denomina.

Sobre o prisma no sentido abstrato, a palavra religião tem seu significado como sendo tudo o que é realizado com frequência e em forma de cultos, atos litúrgicos e símbolos. Na Grécia antiga cultuava-se de forma Politeísta, ou seja, vários Deuses, os quais eram Masculinos e Femininos. Nesta época as guerras eram motivadas por disputas territoriais e não religiosas. Com o advento das Religiões Monoteístas, passou-se a cultuar um único Deus, considerado de forma que a universalidade desse Deus teria que ser respeitada. Surgiram conflitos nutridos por uma disputa religiosa entre grupos étnicos, de raça e de crença. A motivação de professar e/ou defender o seu sagrado, proposto de forma extremista, gerava-se guerras intituladas "santas", ou seja, o que se deveria ser instrumento da paz se transformava em situações de conflitos cuja real motivação era de manipulação política e territorial.

$\mathrm{Na}$ idade média, durante a história antiga, os romanos perseguiam os cristãos por conta da intolerância. Durante a era da inquisição, já preceituada pelos Cristãos da Igreja Católica, a inquisição portuguesa numa estimativa de aplicação moderna, condenou infiéis sob acusação de bruxaria, satanismo e rituais contrário à Ordem Canônica da referida Igreja. Em um documento histórico levantado pelo historiador Liorente, referente ao período de 1481 a 1808, a Inquisição Espanhola condenou 341.021 pessoas, das quais 31.912 foram queimadas e 17.659 foram queimadas em efígie. Na Inquisição Portuguesa foram condenados 29.590, das quais 1808 foram queimados e 633 queimados em efígie.

Com a chegada dos Portugueses no Brasil, e consequentemente sua colonização, iniciou-se por parte dos Jesuítas a missão de catequizar os Nativos Indígenas por não aceitarem seus cultos e Deuses, impondo o Cristianismo em suas culturas. Trazidos da África, os negros escravizados eram perseguidos religiosamente e proibidos de cultuarem seu sagrado (Orixás). Nesta mesma época, o Papa em exercício mencionava que os negros não possuíam alma e que eram inferiores à animais. Era considerado "coisas" e instrumento de trabalho, objeto de mercancia. Quando flagrados exercendo o culto ao seus Deuses, estes escravos eram condenados à morte e queimados em fogueiras a mando de inquisidores ligados à Igreja Católica Apostólica Romana.

Dom Pedro I, após suceder seu pai Dom João VI, Outorgou a Constituição em 25 de março de 1824, declarando como religião oficial a Igreja Católica Apostólica Romana a ser a única religião do Império. “A Religião Católica Apostólica Romana continuará a ser a 
Religião do Império. Todas as outras Religiões serão permitidas com seu culto doméstico, ou particular em casas para isso destinadas, sem forma algum exterior do Templo" (BRASIL, 1824)

Inúmeras são as crenças existente no mundo, o que torna árduo o trabalho de quantificar os números de seguidores. A crença é parte fundamental da vida cultural de um povo. Estima-se que dentre dez pessoas no mundo, oito se identificam com um grupo religioso, o que se conclui que a religião tem um papel influente na vida cotidiana dessas pessoas. Podem-se encontrar inúmeras religiões ao redor do mundo, mas a maioria enquadrase em dos dois grupos: as religiões Abraâmicas (islamismo, judaísmo, cristianismo, etc.) ou religiões Indianas (budismo, hinduísmo, etc.). Com a globalização, as fés, assim como as línguas, não mais encontram barreiras geográficas, ganhando de forma rápida o mundo. Nas grandes cidades ao redor do mundo, é muito mais fácil encontrar espaços de cultos de diferentes crenças.

No âmbito deste artigo, vale recuperar as observações de CARLS (2019) segundo o qual, o culto do indivíduo adaptado à ciência moderna e a uma sociedade altamente individualizada e diversificada promove a individualidade e a tolerância à diferença, alçados na promoção de valores religiosos, nos quais a verdade e as reivindicações morais do indivíduo têm precedência sobre reivindicações das religiões tradicionais. Isso quer dizer que a permissão da crença e do culto dada ao indivíduo fornecem as bases para a tomada de decisões na esfera pública. Neste contexto, a presença da diversidade religiosa, no entanto, coloca um problema que ocorre porque todas as religiões, criam reivindicações sobre conhecimento e moralidade. Surge assim a base para o presente estudo: analisar o potencial de prevenção dos conflitos religiosos utilizando como ferramenta principal a educação para a liberdade de crença na sociedade brasileira.

\section{ACERCA DO CONFLITO RELIGIOSO: DEFINIÇÃO E TIPOS}

O conflito ocorre quando algo é contestado. Quando se associa religião a conflito, pode-se esperar que a contestação tenha fundo ideológico, moral e seja pautado na crença. Porém, esta não é toda a definição possível. O conflito religioso é, também, um fenômeno 
complexo que envolve uma combinação de domínios contestados, incluindo poder, personalidade, espaço ou lugar e identidade de grupo que são possibilitadas por várias outras condições, as quais incluem as relações políticas, sociais, econômicas, culturais e psicológicas de uma sociedade (MAYER, 2013).

Outra variável definidora do conflito religioso é a incidência da coletividade. Embora os indivíduos possam ser os principais protagonistas, a união da religião com o conflito implica que os agentes envolvidos não sejam indivíduos, mas indivíduos coletivos, ou seja, grupos ou comunidades (MAYER, 2013).

Quando se analisa rivalidades religiosas, pode-se pontuar que em uma mesma interação de grupos, pode ocorrer conflitos via competição, mas pode ocorrer também cooperação. Para ilustrar, observa-se, por exemplo, que duas religiões podem competir para converter fieis no "mercado religioso". Da mesma forma, deve-se considerar também, a possibilidade de que, duas religiões distintas ou dois grupos dentro da mesma religião, possam cooperar em algumas áreas (por exemplo, caridade), enquanto conflitam em outras (por exemplo, ideologia e / ou ritual) (MAYER, 2013).Em outras palavras, conflitos surgem quando, em certos contextos, uma potente coleção de princípios morais, ideológicos e recursos organizacionais passam a informar, legitimar ou sustentar conflitos baseados na fragmentação e hipercompetitividade das comunidades religiosas. Sendo assim, o conflito é um esboço da intolerância e sua escalada, se materializa na adoção de extremismo ou da radicalização (BOICU, 2019).

Existe um conjunto de parâmetros e características que permitem identificar o surgimento de um movimento religioso turbulento que são propícios a constituição de conflitos. Em suma, nota-se que o conflito religioso é interseccional e abrange um amplo espectro de atitudes hostis ou agressivas, que variam de um desrespeito alteridade a uma suscetibilidade aumentada, mais parecida com a intolerância, discurso hostil, discurso de ódio, atos de violência e até assassinatos em nome da fé (BOICU, 2019).

Rink e Sharma (2018) indicam que os conflitos religiosos se estruturam nos níveis macro, meso e micro. No nível macro, há disputas relacionadas às questões sócio-político; no meso, os conflitos se concentram na religiosidade, na conversão religiosa e na exposição a 'Redes radicais'; por fim, no nível micro é reservado aos fatores psicológicos que determinar a radicalização religiosa.Determina-se ainda, que os perfis dos conflitantes variam de acordo com o nível analisado. Assim, em um nível macro, os conflitos se desenvolvem, 
preponderantemente, a partir das disputas de pessoas marginalizadas politicamente ou economicamente. Similarmente, no nível meso, as pessoas com alto nível de religiosidade e neófitos apresentam maiores probabilidade de se envolverem em um conflito religioso e até de se tornarem extremista. Já no nível micro, pessoas que viveram uma tragédia em sua vida privada ou testemunharam atos de violência também manifestam uma predileção pelo conflito religioso (RINK; SHARMA, 2018).

Como visto, o conflito baseia-se, na afirmação de uma superioridade da religião sobre qualquer outra alternativa espiritual (BOICU, 2019). Essa situação pode ocorrer em um nível inter-religioso (por exemplo, os conflitos entre cristãos e muçulmanos) ou interdenominacionais (que são entrelaçados aos conflitos políticos).

É importante salientar que, o conflito não é necessariamente entre duas ideologias coerentes, conjuntos de crenças e valores ou identidades, embora isso seja possível, como no caso de uma guerra religiosa. O conflito pode ser, e geralmente ocorre, em torno de uma questão específica que envolve as estruturas de valor do culto do indivíduo e de uma religião tradicional. Geralmente, o que está em questão são os valores em que os indivíduos agem na esfera política. Se indivíduos nesta esfera estão agindo com valores conflitantes ao da sociedade, ocorrem conflitos (CARLS, 2019). Estes conflitos, geralmente, estão imbricados na proteção da personalidade (e os direitos que a acompanham) em questões que sejam polêmicas como o direito de nascer e de morrer, com indicativo da discussão em torno do aborto, da eutanásia e da política de controle de natalidade; ou em reação aos contextos das questões familiares em ênfase às relações homo afetivas e aos princípios pedagógicos que alteram culturas e dinâmicas intra e Inter organizacionais. Negociar conflitos entre esses valores é um desafio, isso porque, conflitos religiosos envolvem bens irreconciliáveis que reivindicam legitimidades fundamentais (CARLS, 2019).

Outro fator preponderante, a incidência de conflitos religiosos é a questão dos símbolos religiosos. Conflitos que envolvem símbolos sagrados, especialmente quando envolvem violência, funcionam como marcadores de limite de grupo poderosos para demarcar quem pertence a qual grupo. Quando símbolos sagrados associados à democracia liberal são minados ou atacados, incluindo aqueles que representam a separação entre igreja e estado ou a liberdade de expressão, uma forte reação por parte do estado é legítima e necessária (CARLS, 2019). 


\section{A LIBERDADE DE CRENÇA E A GESTÃO DOS CONFLITOS NO DIREITO BRASILEIRO}

O direito basilar à liberdade de crença e convicção previsto na Constituição Federal de 1988 é extremamente didático. Tal assertiva é possível de ser comprovada com a leitura do Artigo $5^{\circ}$, inciso VI, onde: "é inviolável a liberdade de consciência e de crença, sendo assegurado o livre exercício dos cultos religiosos e garantida, na forma da lei, a proteção aos locais de culto e a suas liturgias" (BRASIL, 1988). Este princípio refere-se aos Direitos Fundamentais de primeira geração que são considerados indisponíveis, aqueles direitos que não podem ser dispostos, que são irrenunciáveis e inalienáveis.

Quando a Constituição Federal menciona que o direito à crença é inviolável, referese a algo que em tese, ou seja, na disposição da norma não pode e não deve ser violado por ser particular a cada cidadão. Todavia, na prática, a quebra da ideia do sagrado que permeia os direitos relacionados à crença é comum justamente pelas questões socioculturais onde cada um defende os seus dogmas (o que acredita) mas de modo equivocado como se a sua fé fosse a correta ou a melhor e isso tende claramente a formação de uma zona de conflitos que muitas vezes não se limita as áreas de convivência e chega aos Tribunais.

Nos dizeres de AGOSTINHO (2020),

O caput do artigo $5^{\circ}$ da Constituição Federal de 1988 garante a inviolabilidade do direito fundamental à liberdade. Tem-se que este direito, tratado em seu sentido amplo, está elencado no decorrer dos incisos que constituem tal dispositivo, apresentando-se de diversas formas, a saber: liberdade de autodeterminação (II), pensamento (IV), religião (VI, VII e VIII), expressão (IX), profissional (XIII), informação (XIV e XXXIII), locomoção (XV, LIV e LXI), reunião (XVI) e associação (XVII, XVIII e $\mathrm{XX}$ ).Em que pese o direito à liberdade de religião ser elucidado nos incisos supracitados, é também amparado por vários Tratados Internacionais, dos quais o Brasil é signatário. Através da Emenda Constitucional nº45, de 08 de dezembro de 2004 , por força da criação do $\$ 3^{\circ}$ do artigo $5^{\circ}$, as convenções internacionais de direitos humanos, passam a se situar no topo da pirâmide normativa nacional, desde que aprovados em cada Casa do Congresso Nacional, em dois turnos, por três quintos dos votos dos respectivos membros. Pode-se, deste modo, mensurar a quão significativa se demonstra a liberdade religiosa no cenário transnacional, ratificando sua posição como direito humano transnacional, inalienável, imprescritível e irrenunciável. Quanto à prática processual, o direito à liberdade religiosa se revela ainda mais instigante, quando entra em colisão com outros direitos fundamentais. Cabe, em síntese, diante de tais hipóteses, a ponderação dos direitos 
conflitantes, valendo-se do princípio da proporcionalidade, de forma a decidir cada questão segundo suas particularidades.

É fato que a Constituição Federal protege o direito de quem crê, de quem não crê, do que tem fé, do que diz não ter, daquele que professa sua religião ou deseja mudar, dos que professam sua ideologia e até mesmo suas formas teológicas porque a verdade da lei é que todos os direitos são importantes e são protegidos. Entretanto, esta proteção tem limites, porque mesmo os Direitos Fundamentais não são absolutos afinal, podem ser relativizados a depender da situação extrema no caso concreto e é a própria Constituição Federal no inciso oitavo do referido artigo quinto que diz isso ao dispor que ninguém será privado de direitos por motivo de crença religiosa ou de convicção filosófica ou política, salvo se as invocar para eximir-se de obrigação legal a todos imposta e recusar-se a cumprir prestação alternativa, fixada em lei (BRASIL,1988).

Anterior à Constituição Federal e acima dela como norma sobre direito está a liberdade religiosa assegurada na Declaração Universal dos Direitos Humanos de 1948 (2020) em seu artigo oitavo onde:

Todo ser humano tem direito à liberdade de pensamento, consciência e religião; este direito inclui a liberdade de mudar de religião ou crença e a liberdade de manifestar essa religião ou crença, pelo ensino, pela prática, pelo culto e pela observância, em público ou em particular.

Ou seja, esse documento universal que serve de esteio para as relações internacionais do nosso país conforme o descrito na Constituição de 1988 em seu Art. 4º, II (BRASIL,2020), é a garantia de que todas as pessoas podem crer, manifestar, defender a sua crença e proferir publicamente as suas convicções sejam ela religiosas ou não. Nessa linha de raciocínio, afirma-se que a liberdade religiosa é um conceito que garante e assegura a laicidade do Estado e concomitantemente atribui ao cidadão brasileiro e aos que estejam no Brasil licitamente o direito de manifestar e defender livremente sua fé.

$\mathrm{Na}$ continuidade dessa linha de raciocínio a respeito da liberdade de crer no Brasil é essencial trazer à baila a diferença entre laicidade e laicismo. Por laicidade entende-se como um Estado não confessional e que assume a neutralidade perante as religiões, vislumbrando-se o respeito a todos os credos, inclusive pela ausência de ateísmo e agnosticismo. Por laicismo entende-se que o Estado não confessional se apresenta uma postura de intolerância ou tolerância religiosa, vislumbrando-se uma forma negativa contrária do que se mostra em 
relação a laicidade. No Brasil, é comumente visível em salas dos Órgãos do Poder Judiciário a presença de "Crucifixos", símbolo do Catolicismo, que sobre o prisma da neutralidade, apresenta-se como um fator negativo para a Gestão de Soluções de Conflitos, maculando a laicidade do Estado Brasileiro.

Embora já tenha sido afirmado em parágrafos anteriores que o direito ao culto, a adoração, ao sagrado, ou em síntese, à prática religiosa, é respaldado pela Constituição Federal de 1988 é importante falar a respeito do tratamento dado pelo Código Penal ao desrespeito a esses princípios sempre que a conduta ativa ou omissiva do indivíduo configurar ilícito penal.O Código Penal, em seu artigo 208, prevê a quem pratique a discriminação religiosa, pena de detenção, conforme letra:

Escarnecer de alguém publicamente, por motivo de crença ou função religiosa; impedir ou perturbar cerimônia ou prática de culto religioso; vilipendiar publicamente ato ou objeto de culto religioso é penalizada com detenção de 1 mês a um ano ou multa. Se houver emprego de violência, a pena é aumentada em um terço, sem prejuízo da correspondente à violência (BRASIL, 1940).

Através de pacto realizado junto a ONU, o Brasil como Estado Nacional, respeita o texto estabelecido na Declaração Universal dos Direitos Humanos. Ainda há a Lei $n^{\circ}$ 9.459, de 13 de maio de 1997, que traz na letra do seu artigo $1^{\circ}$ : “Art. $1^{\circ}$ Serão punidos, na forma desta Lei, os crimes resultantes de discriminação ou preconceito de raça, cor, etnia, religião ou procedência nacional" (BRASIL, 1997).

Uma outra óptica precisa ser pontuada e com destaque para preencher os fundamentos do presente trabalho e ela reside justamente no fato de ser o Brasil um país pluralista, um Estado laico que também é composto por diferentes grupos étnicos. Tudo isso envolto no contexto de uma sociedade globalizada que é a tônica dos dias atuais, o que contribui sobremaneira para o surgimento dos conflitos reais causados na maioria das vezes por pessoas radicais ou grupos "ditos" religiosos que, ao distorcerem o Direito Fundamental à liberdade de crença e condicionarem as pessoas ao seu redor ou comando a terem o mesmo comportamento geram insegurança em detrimento à liberdade fruto da paz social que é o objetivo maior de um Estado Democrático de Direito.

A opressão leva as pessoas a serem renegadas pela sua própria identidade e individualidade, sendo atacadas no direito de cultuar o seu sagrado e, por conseguinte nas suas garantias fundamentais asseguradas no corpo da Constituição. Segundo levantamento 
feito pelo Correio Braziliense (BRASIL,2020), estudos realizados pelo Ministério da Mulher, da família e dos Direitos Humanos (MMFDH) apontam que o Brasil mostra na realidade as faces da intolerância religiosa com agressões físicas, xingamentos, depredações, destruições de imagens, tentativas de homicídio e incêndios criminosos. Uma triste realidade com estatísticas que contrariam o preconizado na legislação como liberdade fundamental e segundo o mesmo jornal (BRASIL 2020) tem no Brasil como cidades campeãs Natal, com 191 casos, seguido de São Paulo, com 91 e Rio de Janeiro com 61. Desde 2015, Natal lidera o ranking e as outras duas regiões têm rodiziado o segundo e terceiro lugar. No ano de 2018, o Disque 100 (Disque Direitos Humanos) registrou 506 casos. Entre os segmentos mais atingidos estão umbanda, com 72 denúncias, candomblé com 47, testemunhas de Jeová, com 31, matrizes africanas, com 28 e outros segmentos evangélicos, com 23.

A religião de um povo é algo muito marcante culturalmente. Uma forma simples de ataque a um determinado grupo é fazê-lo diretamente ao seu sagrado, ou seja, a religião. Fica claro e notório que a xenofobia tem relação direta com a intolerância religiosa. Grupos com pensamentos fanáticos e conservadores criam aversões aos povos que adentram seus territórios através de ondas migratórias oriundas das mais variadas situações (guerra, estudos, trabalho, etc.), buscando na religião subterfúgios com os quais objetivam restringir ou até mesmo impedir o ingresso dos mesmos nos territórios.

O Ministério dos Direitos Humanos, pautado na Lei 12.288/2010, que efetivou o Estatuto da Igualdade Racial no Brasil, promove ações e Políticas Públicas nos âmbitos administrativos Municipal, Estadual e Federal, referentes às questões raciais com políticas afirmativas e permanentes e com projetos direcionados à Sociedade Civil. Trabalho de orientação, sobretudo em relação à conscientização da igualdade racial num país de multiplicidade sociocultural, é direcionado para um público específico alvo de intolerância e xenofobia, como, por exemplo, os financiamentos para a inclusão de negros, indígenas, refugiados e demais minorias no ensino superior por meio de cotas.

Ao estudar conflitos religiosos, Cunha (2012) identificou uma série de situações em que a intolerância religiosa leva à propagação de conflitos, cujas resoluções só aconteceram por meio da intervenção do Judiciário. O primeiro caso que ele utilizou como exemplo diz respeito a um bispo da IURD - Igreja Universal do Reino de Deus que em um programa tele transmitido em 1995, chutou a imagem de Nossa Senhora Aparecida, padroeira do Brasil. Por esse ato ele foi condenado a dois anos e dois meses de prisão pelos crimes de discriminação 
religiosa e vilipêndio de imagem. O segundo vem do Rio Grande do Sul, um pedido de Habeas Corpus foi negado ao editor que veiculava ideias odiosas de segregação racial e religiosa contra judeus em seus livros distribuídos pela internet. Ao manter a condenação de um editor de livros que atentava contra a dignidade da comunidade judaica, o Supremo afirmou aquilo que a liberdade de expressão e a proibição de censura, previstas na Constituição, não configuram um direito absoluto, situado acima e ao largo do sistema jurídico.

Em 2001, tem-se o terceiro caso emblemático onde um casal de fiéis do candomblé queria registrar a filha com nome africano, mas teve resposta negativa do oficial de registro. Após a judicialização no Tribunal de Justiça do Estado de São Paulo foi dado ganho de causa para os pais. E por último, algo inédito como exemplo da liberdade de crença ocorreu quando o Poder Judiciário Brasileiro reconheceu a validade de um casamento feito nos moldes da Religião Afro-Brasileira.

Em contribuição e continuidade do afirmado, nota-se a seguir duas outras situações fáticas que evidenciaram estar no âmbito da judicialização, do processo propriamente dito a maior parte das possibilidades de resolução dos conflitos religiosos no Brasil que mesmo sendo um Estado laico, na verdade e no cotidiano se apresenta como um Estado de intolerância religiosa. A primeira foi em 2004 onde a Rede Record de Televisão exibiu programas com temas como “Orixás, Caboclos e Guias: Deuses ou Demônios? “Os representantes de religiões de Matrizes Africanas se sentiram extremamente ofendidos e então devidamente representados pelo Instituto Nacional de Tradição e Cultura Afro-Brasileira (Itecab) e o Centro de Estudos das Relações de Trabalho e da Desigualdade (Ceert), juntamente com o Ministério Público, impetraram ação judicial contra a referida Emissora no Tribunal Regional Federal da $3^{a}$ Região - TRF3, que formou o processo registrado com o número: 2004.61.00.034549-6. Após 15 anos de luta judicial, a Rede Record foi condenada e antes que seu recurso chegasse ao STJ-Superior Tribunal de Justiça, o processo foi encaminhado ao Gabinete de Conciliação do TRF3, que promoveu a gestão do conflito resultando em um acordo pacífico, onde a emissora tria como contrapartida de reconhecimento do erro e reparação do dano e veiculação de quatro programas orientativos sobre a cultura das religiões de matrizes africanas, além do pagamento da quantia de 600 mil reais (seiscentos mil reais)a título de indenização para as duas instituições mencionadas. 
Ante tantos exemplos negativos de judicialização fica o questionamento a respeito da viabilidade da adoção dos métodos extrajudiciais de resolução de conflitos nos casos específicos dos desentendimentos gerados a partir de divergências religiosas é possível desde que não violem os Direitos Indisponíveis que são a priori as limitações para a utilização de métodos como a conciliação ou a mediação.Nesse sentido, o Conselho Nacional de Justiça CNJ (BRASIL, 2020) em 2016, deu início através do Tribunal de Justiça de Goiás, em Goiânia, a um programa intitulado "Mediar é divino". O principal objetivo deste programa foi o descapacitar líderes religiosos para serem conciliadores e mediadores, porém, não apenas de desentendimentos voltados para conflitos religiosos. As aulas foram ministradas por instrutores formados pelo Conselho Nacional de Justiça (CNJ) e com base nas diretrizes de na resolução $\mathrm{n}^{\circ} 125$ (do CNJ) que foi criada no ano de 2010 como política judiciária para a solução de conflitos via métodos extrajudiciais de resolução de conflitos. Outros tribunais estaduais como o Distrito Federal (TJDFT), Paraná (TFPR), Mato Grosso do Sul (TJMS), adotaram o programa e já formaram turmas de líderes religiosos como Conciliadores e Mediadores.

O interessante e relevante para o presente estudo é que os gestores do curso formador se preocuparam em colocar os integrantes que eram líderes religiosos numa única turma com o objetivo maior de combater a intolerância religiosa e reforçar o respeito a identidade de crença por meio da empatia e solidariedade durante o processo preparatório para formar uma nova forma de pensar e interagir.

De outra via, percebe-se que antes da adoção dos meios de resolução extrajudicial dos conflitos seria muito mais eficaz a prevenção dos conflitos através da educação para o convívio com as diferenças. Como afirma Milani (2020), o maior desafio da humanidade neste século XXI é aprender a conviver com as diferenças e é na escola, por meio de ações pedagógicas, que isso pode ser trabalhado. Afinal, a intolerância religiosa existe e se manifesta também no cotidiano escolar e é a escola o ambiente mais propício depois da família segundo a própria Constituição Federal em seus artigos 205 e 227 (BRASIL,2020) para o desenvolvimento do respeito às diferenças, crenças e identidades dos indivíduos enquanto cidadãos detentores de direitos e deveres no nosso Estado.

Por essas razões, será abordada adiante a importância da educação e de suas práticas pedagógicas desde a primeira infância para criar a consciência nos nossos cidadãos desde cedo sobre a essencialidade do respeito ao nosso Estado laico e indo além das nossas 
individualidades que nos tornam únicos e que são ao mesmo tempo direitos fundamentais consagrados na nossa Lei maior.

\section{A EDUCAÇÃO E SUAS PRÁTICAS COMO ESTRATÉGIA DE PREVENÇÃo dE CONFLITOS RELIGIOSOS}

A área de concentração do direito que discute as questões da gestão de conflitos está voltada para o estudo da gestão de conflitos como instrumento de transformação das práticas profissionais no sistema judiciário. Contempla os procedimentos aplicados pelo Poder Judiciário nos processos de gestão e solução de conflitos, como também a discussão das políticas de inovação de conflitos estabelecidos pelo Conselho Nacional de Justiça. Aborda os mecanismos extrajudiciais aplicados na solução de conflitos e discute os instrumentos e técnicas de resolução utilizados, entre eles o instrumento de negociação, conciliação, mediação e arbitragem. Discute também, o papel da justiça comunitária e suas contribuições no processo de resolução de conflitos de modo participativo e legítimo. E é exatamente este o contexto em que esta pesquisa será desenvolvida.

No âmbito religioso, recentemente, os mecanismos de resolução / reconciliação foram adotados na seara da gestão. Esses mecanismos desenvolvem ações junto aos grupos que causam os conflitos e os que são alvos da violência (MAYER, 2013). E a educação é uma das áreas que mais possibilitam a gestão, do ponto de vista preventivo.

Nesse sentido, cabe analisar o papel da educação no auxílio à resolução de conflitos que se referem à temática da religião. No que tange essa discussão, há os que defendam a educação laica e os que acreditam na importância de uma formação religiosa específica nas instituições de ensino brasileiras.

Comungando com a Constituição Federal de 1988 e com a Lei de Diretrizes e Bases Nacionais da educação (lei n. 9.994/1996), a Base Nacional Comum Curricular (BNCC) apresenta a discussão do ensino religioso com o propósito de assegurar à diversidade cultural religiosa combatendo o preconceito, a exclusão e a intolerância. Considerando as competências gerais do documento, propõe os seguintes objetivos para área do ensino religioso:

a) Proporcionar a aprendizagem dos conhecimentos religiosos, culturais e estéticos, a partir das manifestações religiosas percebidas na realidade dos educandos; b) Propiciar conhecimentos sobre o direito à liberdade de 
consciência e de crença, no constante propósito de promoção dos direitos humanos; c) Desenvolver competências e habilidades que contribuam para o diálogo entre perspectivas religiosas e seculares de vida, exercitando o respeito à liberdade de concepções e o pluralismo de ideias, de acordo com a Constituição Federal; d) Contribuir para que os educandos construam seus sentidos pessoais de vida a partir de valores, princípios éticos e da cidadania. (BRASIL, 2020, p. 436)

A BNCC apresenta a preocupação com os pressupostos éticos que envolvem o tema, no sentido de não privilegiar nenhuma religião ou crença em detrimento de outra. Seguindo, assim, a permanência do diálogo como mediador e articulados de todo processo, auxiliando de forma direta a diminuição dos conflitos religiosos nos ambientes escolares e, como reflexo, em toda a sociedade. Como estratégia observa-se na BNCC a busca da problematização em relação às diferentes representações sociais e culturais religiosas para a diminuição da discriminação e dos conflitos religiosos usando como estratégia a valorização e o respeito às diferentes histórias e crenças que envolvem a grande diversidade religiosa no Brasil. Ainda de acordo com os estudos da BNCC, a partir desse entendimento de ensino religioso pretende-se realizar a formação integral dos estudantes para que possam conviver em sociedade de maneira democrática e cidadã. Nesse sentido, as estratégias pedagógicas devem promover o conhecimento na perspectiva da garantia dos direitos humanos, do respeito e da manutenção da paz. Dessa forma, o componente curricular do ensino religioso para o Ensino Fundamental deve garantir ao estudante o desenvolvimento das seguintes competências específicas:

1. Conhecer os aspectos estruturantes das diferentes tradições/movimentos religiosos e filosofias de vida, a partir de pressupostos científicos, filosóficos, estéticos e éticos. 2. Compreender, valorizar e respeitar as manifestações religiosas e filosofias de vida, suas experiências e saberes, em diferentes tempos, espaços e territórios. 3. Reconhecer e cuidar de si, do outro, da coletividade e da natureza, enquanto expressão de valor da vida. 4. Conviver com a diversidade de crenças, pensamentos, convicções, modos de ser e viver. 5. Analisar as relações entre as tradições religiosas e os campos da cultura, da política, da economia, da saúde, da ciência, da tecnologia e do meio ambiente. 6. Debater, problematizar e posicionar-se frente aos discursos e práticas de intolerância, discriminação e violência de cunho religioso, de modo a assegurar os direitos humanos no constante exercício da cidadania e da cultura de paz. (BRASIL, 2020, p. 437)

Embora essas competências sejam relevantes como estratégia da diminuição dos conflitos religiosos dentro e fora da escola, Cunha (2018) apresenta algumas críticas em relação à maneira como o ensino religioso está previsto para o Ensino Fundamental. Um desses apontamentos se deve ao fato de o ensino religioso ser pensado no Ensino 
Fundamental separadamente do Ensino Médio. Cunha (2018) assinala que no Ensino Fundamental não estão previstas as disciplinas de filosofia e sociologia, mas essas mesmas disciplinas aparecem no Ensino Médio, embora não sejam cursadas por todos. O autor considera que existe uma "laicidade relativa", pois aponta que mesmos nas instituições escolares onde se é declarado o Estado laico, as práticas religiosas aparecem em celebrações de calendário, orações em reuniões, entre outras situações que acabam favorecendo os grupos religiosos majoritários no país.

Cunha (2018) considera que muitos professores são responsáveis por tentar apresentar ou impor sua religião nas escolas, o que dificulta a construção de um ensino religioso que realmente siga a valorização da diversidade religiosa no país. Nas palavras de Valente (2018, p. 123): “A religiosidade não só atravessa a prática docente, de acordo com a configuração de crenças de cada professor, mas também possui consequências para a socialização das crianças que frequentam o espaço escolar”. Dessa forma, é preciso maior atenção para os cursos de formação de professores e para a necessidade de tratar essas questões na formação, justamente para que o futuro docente entenda a necessidade de se aplicar os seis objetivos apresentados pelo documento da BNCC.

Não há dúvidas de que é na escola que o ensino deve ser trabalhado de forma ética e plural. No entanto, as estratégias de conscientização e problematização da questão deve ser tratada com maior atenção nos cursos de formação de professores. Somente com um trabalho sério que realmente respeite o Estado laico e a diversidade cultural religiosa no país será possível a construção de uma sociedade de respeito e paz.

\section{CONSIDERAÇÕES FINAIS}

Neste artigo procurou-se de forma objetiva trazer o contexto histórico sobre religiões. Explanou-se as de maiores predominâncias no Brasil e no Mundo, suas características, fundamentos e crenças. O Brasil como Estado Laico, oferece canais à sociedade que auxiliam no combate à intolerância religiosa, como o Disque 100 para denúncias. Evidencia-se que um longo e árduo trabalho ainda é necessário ser desenvolvido para combater a todo tipo de conflito religioso e intolerância religiosa de discriminação de qualquer espécie. Promover o conhecimento e o respeito para com o sagrado de cada religião, respaldando a individualidade e a liberdade a culto e crença com equilíbrio. 
O Poder Judiciário tem a responsabilidade da aplicabilidade da Lei nos crimes de intolerância. Aos Operadores do Direito fica a missão de desenvolver mecanismos que auxiliem na promoção da paz entre grupos religiosos, através da gestão de soluções de conflitos. Evidencia-se que na prática, a gestão de soluções de conflitos sobre Direitos Indisponíveis, tais como o direito à liberdade de crença, poderá a consenso, a possibilidade de uma conciliação pacífica sem violar o direito das partes.

A educação tem papel fundamental no trabalho da promoção da valorização da diversidade cultural religiosa brasileira e pode ser sim utilizada como estratégia da diminuição dos conflitos. No entanto, é necessário um melhor trabalho na formação inicial dos professores, para que realmente sejam promotores de uma educação laica, pautada no respeito e na paz. As diferenças culturais, conflitos e inseguranças, são as causas geradoras de violências e guerras. O que se deveria ser instrumentos de paz, se transformam muitas vezes em situações conflituosas cuja motivação servem de cunho de manipulação políticas e racistas. A intolerância religiosa é só o pano de fundo para grupos fundamentalistas estamparem seus interesses políticos e manipuladores, usando do poder bélico para expor suas opiniões e vontades.

\section{REFERÊNCIAS}

AgOSTINHO, Luiz Otávio Vicenzi de. Análise Constitucional acerca da crise entre a liberdade de crença e o Estado Laico. Disponível em: http://seer.uenp.edu.br/index.php/argumenta/article/view/115/115 Acesso em: 30 mar.2020.

BARBANTI JR, O. Conflitos socioambientais: teorias e práticas. In: Encontro - Associação Nacional de Pós-Graduação e Pesquisa em Ambiente e Sociedade (ANPPAS), 1., 2002, Indaiatuba - SP. Anais...São Paulo - ANPPAS, 2002. p.1-20. Disponível em: $<$ http://www.anppas.org.br/encontro_anual/encontro1/gt/dimensoes_socio_politicas/CONFLI TOS\%20SOCIOAMBIENTAIS\%20-\%20TEORIAS\%20E\%20PR\%C1TICAS.PDF>. Acesso em: 18 out.2017.

BRASIL. Constituição. Constituição da República Federativa do Brasil de 1988. Brasília, DF, $1988 . \quad$ Disponível em: http://www.planalto.gov.br/ccivil_03/constituicao/constituicao.htm. Acesso em: 05 jan. 2020.

BRASIL. Constituição. Constituição da República Federativa do Brasil de 1824. Secretaria de Estado dos Negócios do Império do Brasil a fls. 17 do Liv. $4^{\circ}$ de Leis, Alvarás e Cartas Imperiaes. Rio de Janeiro em 22 de abril de 1824. Disponível em: http://www.planalto.gov.br/ccivil_03/Constituicao/Constituicao24.htm. Acesso em: 05 jan. 2020. 
Declaração Universal de Direitos Humanos. Disponível em: https://nacoesunidas.org/direitoshumanos/declaracao/ Acesso em: 29 mar. 2020.

Decreto-lei no 2.848, de 7 de dezembro de 1940. Código Penal. Diário Oficial da União: República Federativa do Brasil: Poder Legislativo, Rio de Janeiro, 7 de dezembro de 1940; $119^{\circ}$ da Independência e $52^{\circ}$ da República. Disponível em: http://www.planalto.gov.br/ccivil_03/decreto-lei/del2848compilado.htm. Acesso em: 19 mar. 2020.

Lei no 13.105 de 16 de março de 1015. Código de Processo Civil. Diário Oficial da União: República Federativa do Brasil: Poder Legislativo, Brasília, 16 de março de 2015; $194^{\circ}$ da Independência e $127^{\circ}$ da República. Disponível em: http://www.planalto.gov.br/ccivil_03/_ato2015-2018/2015/lei/113105.htm. Acesso em: 19 mar. 2020.

Lei $\mathrm{n}^{\circ} 9.459$, de 13 de maio de 1997. Altera os arts. $1^{\circ}$ e 20 da Lei $\mathrm{n}^{\circ} 7.716$, de 5 de janeiro de 1989, que define os crimes resultantes de preconceito de raça ou de cor, e acrescenta parágrafo no art. 140 do Decreto-lei e 2.848, de 7 de dezembro de 1940. Diário Oficial da União: República Federativa do Brasil: Poder Legislativo, Brasília, Seção 1, p.9901, 1997. Disponível em: http://www.planalto.gov.br/ccivil_03/_ato20152018/2015/lei/113140.htm. Acesso em: 19 mar. 2020.

Lei $n^{0}$ 13.140, de 26 de junho de 2015. Lei da Mediação; Lei de Mediação. Dispõe sobre a mediação entre particulares como meio de solução de controvérsias e sobre a auto composição de conflitos no âmbito da administração pública; altera a Lei $n^{\circ} 9.469$, de 10 de julho de 1997, e o Decreto $\mathrm{n}^{\circ} 70.235$, de 6 de março de 1972; e revoga o $\S 2^{\circ}$ do art. $6^{\circ}$ da Lei n ${ }^{\circ}$ 9.469, de 10 de julho de 1997. Diário Oficial da União: República Federativa do Brasil: Poder Legislativo, Brasília, Seção 1, p.4, 2015. Disponível em: https://www2.camara.leg.br/legin/fed/lei/2015/lei-13140-26-junho-2015-781100-normapl.html. Acesso em: 19 mar. 2020.

Lei $\mathrm{n}^{\circ} 13.129$, de 26 de maio de 2015. Altera a Lei $\mathrm{n}^{\circ}$ 9.307, de 23 de setembro de 1996, e a Lei $\mathrm{n}^{\circ}$ 6.404, de 15 de dezembro de 1976, para ampliar o âmbito de aplicação da arbitragem e dispor sobre a escolha dos árbitros quando as partes recorrem a órgão arbitral, a interrupção da prescrição pela instituição da arbitragem, a concessão de tutelas cautelares e de urgência nos casos de arbitragem, a carta arbitral e a sentença arbitral, e revoga dispositivos da Lei n ${ }^{\circ}$ 9.307, de 23 de setembro de 1996. Diário Oficial da União: República Federativa do Brasil: Poder Legislativo, Brasília, 26 de maio de 2015; $194^{\circ}$ da Independência e $127^{\circ}$ da República. Disponível em: http://www.planalto.gov.br/ccivil_03/_Ato20152018/2015/Lei/L13129.htm. Acesso em: 19 mar. 2020.

Lei $\mathbf{n}^{\circ}$ 9.394, de 20 de dezembro de 1996. Estabelece as diretrizes e bases da educação nacional. Diário Oficial da União, Brasília, 23 de dezembro de 1996. Disponível em: 〈http://www.planalto.gov.br/ccivil_03/leis/L9394.htm>.

Base Nacional Comum Curricular: Educação é a base. Disponível em: <http://basenacionalcomum.mec.gov.br/images/BNCC_EI_EF_110518_versaofinal_site.pdf> . Acesso em: 04 abr. 2020. 
BOICU, Dragoş. Intra denominational religious conflict and the need for self-assertion. European Journal of Science and Theology, v.15, n.5, p.95-105, 2019. Disponível em: http://www.ejst.tuiasi.ro/Files/78/10_Boicu.pdf

CARLS, Paul. Modern Democracy as the Cult of the Individual: Durkheim on religious coexistence and conflict. Critical Researchon Religion, v. 7, n. 3, p. 292-311, 2019. Disponível em:https://journals.sagepub.com/doi/full/10.1177/2050303218823069. Acesso em: 19 mar. 2020.

CUNHA, Luiz Antônio. Três décadas de conflitos em torno do ensino público: laico ou religioso?.Educ. Soc. [online]. 2018, vol.39, n.145, pp.890-907. EpubNov 14, 2018.Disponível em: <http://www.scielo.br/pdf/es/v39n145/1678-4626-es-es010173302018196128.pdf>. Acesso em 03 abr. 2020.

CUNHA, Christina Vital da. Conflitos religiosos e a construção do respeito à diversidade: breve histórico e iniciativas recentes. Comunicação e Transformação Social, São Leopoldo: Editora Unisinos, 2012, p. 95-122. Disponível em: https://s3.amazonaws.com/academia.edu.documents/38004925/Conflitos_religiosos_e_a_cons trucao_do_respeito_a_diversidade.pdf?response-contentdisposition=inline \%3B\%20filename\%3DConflitos_religiosos_e_a_construcao_do_r.pdf\&XAmz-Algorithm=AWS4-HMAC-SHA256\&X-AmzCredential=ASIATUSBJ6BAEHZPF34Y\%2F20200325\%2Fus-east$1 \% 2$ Fs 3\%2Faws4_request $\& X-A m z-D a t e=20200325 T 132959 Z \& X-A m z-$ Expires $=3600 \& X-$ Amz-Security-

Token=IQoJb3JpZ2luX2VjEH0aCXVzLWVhc3QtMSJHMEUCIFu6Codb9DtGBwirrirvfob Ojsutt8EqGVUU9GUACkOCAiEA13wXx9IZxNvi5PraiaU\%2FE12XWvAswNtGmPjYDgC \%2B9NIqtAMIdhAAGgwyNTAzMTg4MTEyMDAiDON\%2FVI1 yRYfM72hBNCqRAzVq wcWWNQNhEWmazjkfx9tHAs4XR\%2BnZtcNY05uOcgrw01wnhV31boVfKj9Zs\%2FnLQb rpjmMF5t\%2BcYvTuHl\%2Bjfgojf8BNsCj9vOvMdym\%2BtjvQvPNO41RA7Qj2Q7UuEZha EEjH16NDuZmF16UcoR\%2FITBKShZkgFSfNfSsNZoheSX1AXRP3A5fa0jyfnXvB5D3704 BDpctx\%2BU0vOBvji\%2FsEBsTygUv1ysgTpv97TEb0Cl2\%2BK13XmhVJBWv\%2BUranc ZNKhlwmzHNrwE9Wlw\%2FoofKGw1vM\%2Fkm5JgG0q3u3AAL9i3Gmh74TbkoRapYrU9 3Vo8dNAyrhURw2VQKzrt2fiaL6f064w7F9wHAKDbDyZUQetw4iCNdhF\%2FynQR9M2xr hUhOgit8tp1QQbzRLTvXNpUOHifCCFPh9RF4rl7mpjWk0x834mGnVadvDRJvHsqlBAgM 2Tt1mJMnE7vghj5G8JmfulH\%2FfYf9mhEC7MKB754\%2FiChL7F\%2BjPer8VC\%2Binz\%2 BfaMUIIPVSpey\%2FaQyAK2tyKyDPD51EIMJ2g7fMFOusBC3hP5XvNdjCYHURM1Y5h3 BYEpNRxiKDiL2CwVqqBPIx90dXEG7FeOAh4VF00mj34ItFxFdJK1LwxUnnM3o9gpyiB WUig5oWtqqINpfOKzyGDtlVWyY4P4\%2FUbebxtusYOWKU3Kh9Ti01brq0ZWjDwIeUPF SZGEgenXaXdWTKAe9XRIWw0B8Wn4nsnTSwotNKTFyM13vIOPVpaxuhx\%2BiVGPAn ZjYzs3XVleCxsHsECZS0ChFM3iOlgGRTE\%2ByAFGm1oWb0UwHEOeGIO6UEC7AUA \%2FQ0r75c5XUrqbZg6nuYoMU\%2BHhwpCH31YsVMaXA\%3D\%3D\&X-Amz-

SignedHeaders $=$ host $\& X-A m z-$

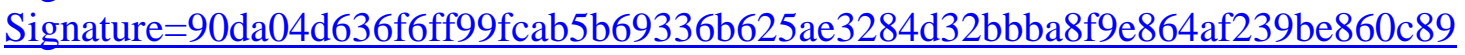

Acesso em: 19 mar. 2020.

CNJ - Conselho Nacional de Justiça. "Justiça treina religiosos para a mediação de conflitos". cnj.jus.br. Disponível em: https://www.cnj.jus.br/justica-treina-religiosos-para-amediacao-de-conflitos/. Acesso em 16 de março de 2020. 
GRANJA, S. I. B.; WARNER, J. A hidropolítica e o federalismo: possibilidades de construção da subsidiariedade na gestão das águas no Brasil?.Revista de Administração Pública, Rio de Janeiro, v. 40, n. 6, p. 1097-1121, 2006. Disponível em: <http://bibliotecadigital.fgv.br/ojs/index.php/rap/article/view/6873 > . Acesso em: 18 out.2017.

JUSBRASIL. “Art. 5, inc. VI da Constituição Federal de 88”. jusbrasil.com.br. Disponível em: https://www.jusbrasil.com.br/topicos/10730845/inciso-vi-do-artigo-5-da-constituicaofederal-de-1988. Acesso em 14 de março de 2020.

JUSTIÇA FEDERAL - Tribunal Regional Federal da $3^{\text {a }}$ Região. "Consulta Processual".http://web.trf3.jus.br/. Acesso em 15 de março de 2020.

MAYER, Wendy. Religiousconflict: Definitions, problems, andtheoretical approaches. 2013.

RINK, Anselm; SHARMA, Kunaal. The determinantsofreligiousradicalization: EvidencefromKenya. JournalofConflictResolution, v. 62, n. 6, p. 1229-1261, 2018. Disponível em: https://journals.sagepub.com/doi/full/10.1177/0022002716678986. Acesso em: 19 mar. 2020.

VALENTE, Laicidade, Ensino Religioso e religiosidade na escola pública brasileira: questionamentos e reflexões. Pro-Posições vol.29 no.1 Campinas Jan./Apr. 2018. Disponível em: 〈http://www.scielo.br/pdf/pp/v29n1/0103-7307-pp-29-1-0107.pdf>. Acesso em: 05 abr. 2020.

VARGAS, G. M. Conflitos sociais e sócio-ambientais: propostas de um marco teórico e metodológico. Sociedade \& Natureza, v. 19, n. 2, p. 191-203, 2007. Disponível em: <http://www.seer.ufu.br/index.php/sociedadenatureza/article/view/9284>. Acesso em: 18 out.2017.

WIENS, I. K. A gestão de resíduos da construção civil: iniciativas na bacia hidrográfica Tietê-Jacaré e uma proposta para o município de Bauru (SP). 2008. 147 f. Dissertação (mestrado em engenharia de produção) - Universidade Estadual Paulista, Faculdade de Engenharia, 2008. Disponível em: http://hdl.handle.net/11449/136668 